\title{
The Need for Three Separate Parallel WAD Ratings of Whiplash Injuries to Cervical, Lumbosacral, and Thoracic Spine in Clinical Assessments of Injured Motorists
}

\author{
Zack Z. Cernovsky, Stephan C. Mann, Varadaraj R. Velamoor, and L. Kola Oyewumi
}

\section{ABSTRACT}

Background: The prevailing classification of whiplash associated disorder (WAD) focuses solely on neck injuries, thus implying that injuries to other spinal regions are relatively inconsequential. In fact, some whiplash studies exclude patients with injuries to lower spine. We examined whiplash pain locations of injured motorists and their statistical correlates.

Method: De-identified archival data of 158 injured motorists (57 men and 101 women; mean age 39.4 years, $S D=12.5$ ) were reviewed statistically. Their motor vehicle accidents (MVAs) occurred 7 to 194 weeks previously (mean=50.7 weeks, SD=38.5), but all still experienced active whiplash symptoms requiring therapy.

Results: The most frequently reported locations of whiplash pain were the head $(89.9 \%)$, neck $(88.6 \%)$, shoulders $(80.4 \%)$, and lower back $(77.8 \%)$. WAD studies that exclude patients with lower back pain might exclude about $\mathbf{8 2 . 9 \%}$ of injured motorists: the remaining $17.1 \%$ of patients with whiplash injury only to the neck are presumably those less adversely affected by the MVA than patients with pain in multiple locations. No correlations of high or moderate magnitude were detected among the various pain locations. Furthermore, no high or moderate correlations were observed between clinical variables (including 2 neuropsychological symptoms scales) and reports of headache or pain in the neck or in lower back.

Discussion and Conclusions: The prevailing WAD classification system needs to be renamed as specific to neck injury only: WAD-C. Parallel WAD classification systems need to be introduced separately for the lumbosacral spine (as WAD-LS) as well as the thoracic spine (as WAD-T) to improve diagnostic descriptive precision of clinical WAD assessments and of their research applications.

Keywords: whiplash, WAD grades, cervical spine, lumbosacral spine, thoracic spine.

\section{INTRODUCTION}

Since it is generally believed that the higher the injury on the spinal cord, the greater the dysfunction, errors can occur in clinical assessments. Defining whiplash as an injury only to the cervical spine is a common error that confounds the results of scientific research on the whiplash syndrome. This problem is compounded if patients who also report lower back pain are excluded from the sample. The exclusion of whiplash patients who also sustained lumbar or sacral injuries restricts the researcher to a subgroup of relatively less severely injured whiplash patients, who report no midback or lower back pain.

A hospital study by Fakharian's team reviewed 91 patients with spinal fractures from severe motor vehicle accidents (MVAs) [1]. Most of these fractures resulted from [1]. region [2].
Submitted : January 31, 2020

Published : February 11, 2021

ISSN: 2593-8339

DOI: $10.24018 /$ ejmed.2021.3.1.699

\section{Z. Z. Cernovsky*}

Dept. of Psychiatry, Western University, London, Ontario, Canada. (e-mail: zcernovs@uwo.ca)

S. C. Mann*

Central Montgomery Behavioral

Heath, Norristown, PA, USA.

(e-mail: smann1234@aol.com)

V. R. Velamoor

Dept. of Psychiatry, Laurentian and Lakehead Universities, and Western University, Ontario, Canada. (e-mail: velamoorraj@gmail.com)

L. K. Oyewumi

Departments of Psychiatry, Biomedical and Molecular Sciences, and Psychology, Queen's University, Ontario, Canada.

(e-mail: oyewumik@ ${ }^{@}$ queensu.ca)

*Corresponding Authors

car rollover $(70.3 \%)$. Car collisions accounted for the remaining cases (29.7\%). Within Fakharian's sample of 91 patients, the spinal fracture most often occurred within the lumbar region $(64.8 \%)$, followed by the thoracic $(20.9 \%)$, and then the cervical (14.3\%). Four patients (4.3\%) had multiple spinal fractures. The lumbar region was consistently the most frequently injured location within the spine, not only in car rollovers, but also in regular collisions

A study of post-MVA patients in the UK by Robertson's team (2002) involved 126 motorcyclists and 383 car drivers or passengers who were involved in MVAs requiring hospitalizations exceeding 3 days [2]. The car occupants sustained injuries predominantly in the cervical spine while the motorcyclists' injuries clustered in the thoracic spinal 
In the German language, whiplash injury is pertinently described as "Schleudertrauma" which highlights the sense of the patient being jolted forcefully by the impact, abruptly propelled, hurled, catapulted, or flung (based on the German verb schleudern). If the patient's car is rear-ended by another vehicle and jolted forward, the patient's head and body appear to be violently thrust backwards against the seat. The head may sustain impact against the headrest. Subsequently, in the contrecoup, the head and the remainder of the body are thrust in the opposite direction.

Frontal collisions may involve a sudden complete deceleration of the vehicle during which the patient's body is violently catapulted against the seatbelt, the deployed airbag, or even the dashboard. Limbs might be injured by impact against the dashboard.

Thus, in frontal or rear collisions, the whiplash involves a violent acceleration or deceleration resulting in injuries to ligaments, muscles, spinal discs, or in nerve impingements, and sometimes in displaced or nondisplaced vertebral fractures.

Freeman's team [3] studied the incidence and type of spinal injuries sustained by roller-coaster riders in amusement parks, i.e., injuries resulting from relatively lowlevel accelerations below the average level of collision impact experienced by chronic post-MVA patients. Freeman's study focused on 39 roller-coaster riders who sustained spinal injuries [3]. Based on a medical records review, 28 of the 39 riders $(72 \%)$ sustained injuries to disks in cervical spine (herniated disks and symptomatic disk bulges). Cervical spine injuries also included one case of a vertebral body compression fracture at C5 and one case of a spinal cord contusion secondary to a displaced os odontoideum. In the lumbar spine, the most frequent injury was a symptomatic disk bulge $(20 \%)$, followed by vertebral body compression fracture (18\%), and disk herniation (13\%) [3]. These spinal injuries from roller-coaster rides presumably occurred only in an especially susceptible and very tiny subset of the relatively healthy general population. The calculated risk of significant spinal injury in rollercoaster rides ranged only from .00006 to .00013 .

Fast's team [4] evaluated the whiplash impact of a simulated rear-collision on the lumbar spine of an unembalmed human cadaver. In their experiments, the collision was presumably not forceful enough to cause vertebral fractures, but the impact was found of sufficient momentum to cause soft tissue injuries to lumbar spine [4].

In more violent collisions, spinal fractures of lumbar spine can occur. A case history was published elsewhere [5] of a 57 year old chemistry teacher driving his Honda Civic, who decelerated on an expressway due to slow traffic ahead, was rear-ended at a high speed by a transport truck, and whose Honda was then propelled by the rear impact into another transport truck ahead. Hence this patient experienced both a rear and frontal collision. He sustained compression fractures of lumbar vertebrae.[5] As also suggested by Fakharian's research, [1] the MVA injuries to lumbar spine can be as frequent and as medically serious as those to the cervical spine.

The majority of chronic MVA patients who did not sustain vertebral fractures, do not require post-MVA hospitalization. However, they typically feel extensively disabled due to unrelenting post-accident pain resulting from soft tissue injuries to the spinal region, the pain often lasting for years. The present study examines the anatomic distribution of whiplash pain reported by injured car drivers and passengers.

\section{METHOD}

\section{A. The Patients}

Archival de-identified data from 2017 to 2020 were available on 158 injured motorists (127 drivers, 31passengers). The sample consisted of 57 men and 101 women. Their age ranged from 17 to 69 years, with the average at 39.4 years $(\mathrm{SD}=12.5)$. The impact of the collision was to the side of their vehicle in $36.1 \%$ of the cases, to the rear in $34.8 \%$, to the front in $24.1 \%$, and involved some form of a combined impact in $5.1 \%$ of the cases. No loss of consciousness (LOC) during their MVA was reported by 68 patients $(43.6 \%), 58$ patients $(37.2 \%)$ were uncertain whether or not they had lost consciousness, 26 (16.7\%) reported a brief loss of consciousness, 4 (2.6\%) had lost consciousness for longer than 5 minutes, and no LOC data were available for 2 patients. Their MVA occurred 7 to 194 weeks previously (mean=50.7 weeks, $\mathrm{SD}=38.5$ ), but all still experienced active whiplash symptoms requiring therapies.

\section{B. Locations of Whiplash Pain}

In the archival data, reports of whiplash pain were recorded separately for the following 10 locations: head, neck, shoulders, upper back, lower back, hips, gluteus, upper leg, knees, lower leg.

\section{Other Measures}

Their data included scores on the Subjective Neuropsychological Symptoms Scale (SNPSS) [6], Rivermead Post-Concussion Symptoms Questionnaire [7], [8], Immediate Concussion Symptoms scale [9] Insomnia Severity Index [10], and the PCL-5 measure of PTSD for DSM-5 developed by the U.S. National Center for PTSD [11]. The data also included Items 3, 4, and 5 of the Brief Pain Inventory [12] i.e., the patients' ratings of the worst pain, least pain, and of average pain on a scale from 0 ("no pain") to 10 ("pain as bad as you can imagine") and the patients' ratings on Items 10 to 12 of the Whiplash Disability Questionnaire,[13] i.e., ratings of depression, anger, and of anxiety via scales from 0 ("not at all") to 10 ("always").

The mean scores of our patients on these measures are listed in Table 1.

\section{RESUlts}

\section{A. Distribution of Reported Whiplash Pain}

Only two of the 158 patients (i.e., 1.3\%) reported pain solely in one location. Seven patients (4.4\%) reported whiplash pain in all 10 locations. The mean number of reported pain locations was $5.5(\mathrm{SD}=2.1)$. 
TABLE 1: MEAN SCORES ON CLINICAL MEASURES

\begin{tabular}{|c|c|}
\hline & $\begin{array}{l}\text { Average score } \\
\text { (SD): }\end{array}$ \\
\hline $\begin{array}{l}\text { Rivermead Post-Concussion } \\
\text { Questionnaire [7] }(\mathrm{N}=86)\end{array}$ & $45.8(9.2)$ \\
\hline $\begin{array}{l}\text { Subjective Neuropsychological Symptoms } \\
\text { Scale [6] }(\mathrm{N}=123)\end{array}$ & $20.6(11.1)$ \\
\hline $\begin{array}{l}\text { Immediate Concussion Symptoms scale [9] } \\
\text { Brief Pain inventory [12]: }\end{array}$ & $4.6(1.8)$ \\
\hline Ratings of worst pain & $8.3(1.3)$ \\
\hline Ratings of least pain & $4.4(1.9)$ \\
\hline Ratings of average pain $(\mathrm{N}=157)$ & $6.4(1.5)$ \\
\hline Insomnia Severity Index [10] & $23.8(3.9)$ \\
\hline $\begin{array}{l}\text { PCL-5 measure of PTSD as per DSM5 [11] } \\
(\mathrm{N}=74)\end{array}$ & \\
\hline Whiplash Disability Questionnaire [13]: & \\
\hline Ratings of depression $(\mathrm{N}=156)$ & $8.4(1.5)$ \\
\hline Ratings of anger $(\mathrm{N}=156)$ & $8.5(1.5)$ \\
\hline Ratings of generalized anxiety $(\mathrm{N}=156)$ & $8.8(1.6)$ \\
\hline
\end{tabular}

The frequencies of pain reported in each location are listed in Table 2: the data are arranged from the highest to lowest frequency.

TABLE 2: REPORTS OF WHIPLASH PAIN ACCORDING TO LOCATION

\begin{tabular}{cc}
\hline Location: & \% of patients \\
\hline head & $89.9 \%$ \\
neck & $88.6 \%$ \\
shoulders & $80.4 \%$ \\
lower back & $77.8 \%$ \\
upper back & $70.8 \%$ \\
knees & $36.7 \%$ \\
hips & $35.4 \%$ \\
gluteus & $25.3 \%$ \\
lower leg & $24.7 \%$ \\
upper leg & $20.9 \%$ \\
\hline
\end{tabular}

Head, neck, shoulders, and lower back seem to be the most frequent locations (> 75\% of patients).

Pearson phi correlations among the locations of reported pain were all very low or non-significant. It is important to consider that with large samples such as in the present study, even excessively weak correlations as low as .20 become "significant" at $\mathrm{p}<.01$ (2-tailed), but such correlations account for only about $4 \%$ of variance, and are thus, of very little clinical interest.

It is particularly noteworthy that the reports of headaches were not significantly correlated to pain in any other location (Pearson phi coefficients ranging from -.01 to .15).

With respect to correlates of neck and of lower back pain, the only statistically significant phi correlations (those at $\mathrm{p}<.05$, 2-tailed) were as follows. Neck pain was significantly (but only very weakly) correlated with shoulder pain (.27), pain in upper back (.25), and in lower back (.19). Lower back pain was significantly (but also only weakly) correlated with pain over the gluteus area (.31), hips (.30), pain in upper legs (.20), neck (.19), knees (.19), and lower legs $(.16)$.

Since the correlation of neck pain to lower back pain is very low (.19), the two symptoms can occur independently, as also shown by our frequency data in Table 3.
TABLE 3: PROPORTIONS OF 158 MOTORISTS REPORTING WHIPLASH PAIN

\begin{tabular}{cccc}
\multicolumn{4}{c}{ IN THE NECK OR LOWER BACK } \\
\hline & $\begin{array}{c}\text { Lower back } \\
\text { pain absent: }\end{array}$ & $\begin{array}{c}\text { Lower back } \\
\text { pain present: }\end{array}$ & Sums \\
\hline Neck pain absent & $5.1 \%$ & $6.3 \%$ & $11.4 \%$ \\
Neck pain present & $17.1 \%$ & $71.5 \%$ & $88.6 \%$ \\
Sums & $22.2 \%$ & $77.8 \%$ & $100 \%$ \\
\hline
\end{tabular}

The data indicate that only $22.2 \%$ of whiplash patients had no lower back pain (see the bottom entry in the $2^{\text {nd }}$ column of Table 3 ).

If only patients with neck pain are included in this whiplash sample and those with lower back pain are excluded, merely $17.1 \%$ of the patients who sustained whiplash injuries would remain (see Table 3). Thus, if the whiplash were defined as consisting only of injury to the neck, and if the study would include only patients with neck pain and exclude those with lower back pain (perhaps in order to avoid the confounding effect of pain from the lumbosacral region), then $82.9 \%$ of persons with whiplash injuries would be excluded. The remaining $17.1 \%$ of patients with whiplash injury to the neck (but not to lower back) might presumably be those less adversely affected by the MVA than whiplash patients with pain in more than one location.

Neck pain is a very frequent element of whiplash, albeit less frequent than headaches. Nevertheless, neck pain often occurs jointly with reports of pain in other locations. As shown in Table 3, only $6.3 \%$ of the sample (i.e., 10 of the 158 patients) reported lower back pain in the absence of neck pain.

It is also noteworthy that $5.1 \%$ of the patients ( 8 of 158) reported whiplash pain only in some other region than neck and lower back, see these locations in Table 4.

TABLE 4: PROPORTIONS OF PATIENTS REPORTING PAIN ONLY IN REGIONS OTHER THAN NECK AND LOWER BACK

\begin{tabular}{ccc}
\hline Location: & Number of patients & $\%$ \\
\hline Head & 7 & $4.4 \%$ \\
Shoulders & 5 & $3.2 \%$ \\
Knee & 3 & $1.9 \%$ \\
Upper back & 2 & $1.3 \%$ \\
Hips & 2 & $1.3 \%$ \\
Lower leg & 2 & $1.3 \%$ \\
Upper leg & 2 & $1.3 \%$ \\
\hline
\end{tabular}

These "other" locations involved mostly head and/or shoulders. As mentioned, most patients reported whiplash pain in multiple locations: the average number of pain locations was 5.5 and only 2 of the 158 patients reported whiplash pain in exclusively one location.

Pearson correlations (point biserial and phi coefficients) of headache, neck pain, and lower back pain to other clinical variables are all low, and thus, of very little, if any clinical importance (see Table 5). The only exception maybe the .40 correlation of neck pain to Rivermead's measure of the postconcussion syndrome, perhaps due to the jolting of the head that caused both a neck injury and concussion.

In the calculation of correlation of headaches to the Rivermead score, the Rivermead rating of headache (i.e., Rivermead Item \#1) was removed from Rivermead total score to avoid a misleading inflation of the correlation coefficient. 
TABLE 5: CORRELATIONS OF PAIN LOCATION IN THE NECK, LOWER BACK, AND HEAD TO OTHER CLINICAL VARIABLES

\begin{tabular}{|c|c|c|c|}
\hline & neck & Lower back & head \\
\hline Age & $\begin{array}{c}-.23 \\
\mathrm{p}=.004\end{array}$ & $\begin{array}{c}-.21 \\
\mathrm{p}=.008\end{array}$ & -.12 \\
\hline Gender & .02 & .04 & $.19, \mathrm{p}=.020$ \\
\hline $\begin{array}{l}\mathrm{N} \text { of weeks since accident } \\
\text { Driver versus passenger }\end{array}$ & -.15 & -.14 & -.03 \\
\hline $\begin{array}{l}\text { (driver coded as } 1, \\
\text { passenger as } 2 \text { ) }\end{array}$ & -.02 & $\begin{array}{c}-.16 \\
\mathrm{p}=.047\end{array}$ & .01 \\
\hline \multicolumn{4}{|l|}{ Brief Pain Inventory [12]: } \\
\hline Worst pain & -.02 & $.28, \mathrm{p}<.001$ & .13 \\
\hline Least pain & .06 & $.28, \mathrm{p}<.001$ & $.21, p=.008$ \\
\hline Average pain $(\mathrm{N}=157)$ & -.01 & $.30, \mathrm{p}<.001$ & $.27, \mathrm{p}=.001$ \\
\hline $\begin{array}{c}\text { Insomnia Severity Index } \\
{[10](N=157)}\end{array}$ & .01 & .13 & $.24, p=.003$ \\
\hline $\begin{array}{c}\text { Rivermead Post- } \\
\text { Concussion Symptoms } \\
\text { Questionnaire [7] }(\mathrm{N}=86) \\
\text { Subjective }\end{array}$ & $.40, \mathrm{p}<.001$ & .16 & $.28, p=.010$ \\
\hline $\begin{array}{l}\text { Neuropsychological } \\
\text { Symptoms Scale [6] } \\
\qquad(\mathrm{N}=123)\end{array}$ & $.20, p=.028$ & $.22, p=.014$ & .13 \\
\hline $\begin{array}{c}\text { Loss of consciousness in } \\
\text { the MVA }\end{array}$ & -.12 & .08 & .05 \\
\hline $\begin{array}{l}\text { PCL-5 score for PTSD [11] } \\
\qquad(\mathrm{N}=74)\end{array}$ & $.23, p=.045$ & .17 & .12 \\
\hline \multicolumn{4}{|l|}{ Whiplash Disability } \\
\hline Depression $(\mathrm{N}=156)$ & .02 & .14 & .13 \\
\hline Anger $(\mathrm{N}=156)$ & .06 & $\begin{array}{r}.03 \\
00\end{array}$ & $17 \stackrel{.13}{p=036}$ \\
\hline Anxiety $(\mathrm{N}=156)$ & .15 & & \\
\hline
\end{tabular}

Note: all correlations are based on the total sample of patients $(\mathrm{N}=158)$, unless otherwise indicated. All correlations are non-significant ( $p>.05,2-$ tailed), unless the $\mathrm{p}$ value is listed.

\section{DisCUSSION}

Whiplash pain usually occurs jointly in multiple locations: the average number of locations in this study was 5.5. Only 2 of the 158 patients reported pain solely in one location.

Whiplash pain in the lower back is reported by $77.8 \%$ of patients. A narrow focus on neck pain in the belief that it constitutes the key sign of whiplash injury and the exclusion of patients with whiplash injuries to the lower back, hips, and lower limbs, results in an excessively purified but markedly reduced sample likely to consist largely of patients with less adverse whiplash disabilities. This overly simplistic methodological approach may promote confusion regarding the severity and complexity of the syndrome.

In summary it is a serious error to conceptualize whiplash as implying injury only to the cervical spine. Whiplash occurs when the body is jolted by a violent deceleration or acceleration of the patient's vehicle, with the effect similar to being hurled or catapulted, as captured more accurately by the German term Schleudertrauma (jolting trauma). The German verb schleudern could be translated as hurl, fling, catapult, or forcefully launch.

The concept of the Whiplash Associated Disorder (WAD) that includes neck trauma as the key condition is nosologically untenable as it is too often applied by health care professionals to disregard or dismiss other whiplash injuries such as those involving the lumbar spine with various neuropsychological symptoms. Unfortunately, too many patients are erroneously declared as "free of whiplash injuries" by insurance contracted psychological and medical assessors.
International classification of whiplash associated disorders (WAD) divides whiplash injuries into grade I to grade IV:

Grade 0: No complaints about the neck. No physical $\operatorname{sign}(s)$.

Grade I: Neck complaint of pain, stiffness or tenderness only. No physical sign(s).

Grade II: Neck complaint AND musculoskeletal sign(s). Musculoskeletal signs include decreased range of motion and point tenderness.

Grade III: Neck complaint AND neurological sign(s). Neurological signs include decreased or absent deep tendon reflexes, weakness, and sensory deficits.

Grade IV: Neck complaint AND fracture or dislocation.

The WAD classification achieved substantial medical progress by standardizing assessment of neck injuries in MVAs. However, a major limitation of the WAD system is that the neck complaint is by far regarded as the only significant sign of whiplash severity. The WAD system too often underestimates and misclassifies the severity of chronic injuries, following whiplash that resulted in more severe lumbar than cervical pain, or in sustained lumbar fractures in the absence of fractures to cervical vertebrae. The system of WAD classification as grade I to IV was disseminated by a report of the so called Quebec Task Force (QTF), published by Spitzer et al. in 1995 [14]. This task force consisted of a group of clinicians, scientists and epidemiologists commissioned in 1990 by the Société d'Assurance Automobile du Québec (Quebec Automobile Insurance Corporation) to conduct an exhaustive review of the scientific literature, and to make public policy recommendations regarding the prevention and treatment of whiplash and its associated disorders. Subsequently, in 1998, Freeman, Croft, and Rossignol [15] aptly criticized the QTF report for concluding that whiplash injuries result in "temporary discomfort," are "usually self-limited," and have a "favorable prognosis," and that the "pain [resulting from whiplash injuries] is not harmful".

Such statements are indeed in stark contrast to the daily experiences of clinicians who work with chronic post-MVA patients. Freeman's team [15] underscored several methodological errors in the QTF approach that led to flawed conclusions. For instance, proper studies of prognosis of severely injured MVA patients do not support QTF's statements that WAD pain is "not harmful" or that it is short lived. As confirmed by Freeman's team "the pain apparently is long-lived in a substantial proportion of cases. The degree of harm caused by pain from whiplash injuries is a complex subject that was not investigated by the Task Force." Freeman's team also objected to QTF's use of the term discomfort instead of pain: "using the term discomfort in lieu of pain may be misleading, because it may suggest to some that the pain experienced by individuals with whiplash injury is minimal or trivial" [15].

The Quebec Task Force had enthusiastically presented its results as indicating a rate of recovery of $98.1 \%$ at one year, i.e., the rate of a failure to recover as only $1.9 \%$. Such estimates obviously do not apply to motorists injured in high impact MVAs, especially when injuries other than those only to the neck are included in the concept of whiplash.

Harold Merskey, the founding Editor-In-Chief of Pain 
Research and Management had warned readers as early as 1999 concerning reports commissioned by the insurance industry as "designed to persuade medical and allied health professionals to accept viewpoints that appear overoptimistic and potentially self-serving," see Teasell and Merskey [16].

Our 158 patients should be considered in this context. They were evaluated on average at 50.6 weeks after their MVA: the majority of them could be seen as chronic $(72.8 \%$ had active post-MVA symptoms for at least 6 months). The number of weeks since their MVA was not significantly correlated to the presence of absence of reported pain in the neck (-.15), lower back (-.14), and headaches (-.03).

Certain car insurance company clerks might assume from reports such as that compiled by the QTF that most patients who have not recovered within a year following their MVA are most likely malingerers or that they could be (undiagnosed) psychiatrically ill persons who exaggerate and misrepresent a trivial personal discomfort as legitimate pain.

The definition of whiplash adopted by the QTF was formulated in a somewhat vague manner, as follows: "an acceleration-deceleration mechanism of energy transfer to the neck. It may result from rear-end or side-impact motor vehicle collisions but can also occur during driving or other mishaps. The impact may result in bony or soft tissue injuries (whiplash injuries), which in turn may lead to a variety of clinical manifestations (Whiplash-Associated Disorders)".

The definition refers to "a variety of clinical manifestations" which is, in this respect, logically incongruent with QTF's WAD classification into 4 levels based on the neck injury only. To remedy the flaw, the QTF's WAD system should be renamed as specific to neck injury only: WAD-C. A parallel WAD classification system needs to be introduced, and labelled as specific to lumbosacral spine (WAD-LS), e.g., as follows:

Grade 0: No complaints about the lower back. No physical sign(s).

Grade I: Lower back complaint of pain, stiffness or tenderness only. No physical sign(s).

Grade II: Lower back complaint AND musculoskeletal sign(s). Musculoskeletal signs include decreased range of motion and point tenderness.

Grade III: Lower back complaint AND neurological sign(s). Neurological signs include EMG abnormalities, weakness, sensory abnormalities, and sensory deficits.

Grade IV: Lower back complaint AND fracture or dislocation.

Similar parallel WAD classification system needs to be developed also for the thoracic spine: WAD-T. The study of 126 motorcyclists by Robertson's team [2] suggests that injuries to thoracic spine are relatively more frequent in that clinical group. The WAD-T could be, e.g., as follows:

Grade 0: No complaints about the mid back. No physical $\operatorname{sign}(s)$.

Grade I: Mid back complaint of pain, stiffness or tenderness only. No physical sign(s).

Grade II: Mid back complaint AND musculoskeletal sign(s). Musculoskeletal signs include decreased range of motion and point tenderness.
Grade III: Mid back complaint AND neurological sign(s). Neurological signs include EMG abnormalities, weakness, sensory abnormalities, and sensory deficits.

Grade IV: Mid back complaint AND fracture or dislocation.

The joint use of three parallel WAD grading systems (cervical, lumbosacral, and thoracic, i.e., WAD-C, WAD$\mathrm{LS}$, and WAD-T) would improve the descriptive precision of clinical assessments and of research studies.

Undoubtedly, the QTF's WAD classification system per se has provided an excellent operational (i.e., logically more precise) definition of whiplash injury to the neck, a pragmatic tool for systematic clinical assessments. The unintended and flawed consequence of the old QTF's WAD classification system is its exclusive focus on neck injury: patients with severe or chronic whiplash injuries not fitting into narrow confines of the QTF definition are too often pronounced as "free of whiplash" if neck pain is absent post-accident. For example, the old QTF's whiplash severity determination would be blatantly inaccurate in a case of an MVA patient with cervical WAD grade I (mild neck pain, no cervical fracture, no cervical neurologic signs), but with vertebral fractures in lumbar spine, i.e., deserving the diagnosis of WAD-LS grade IV with respect to lumbar spine.

Whiplash, if conceptualized as the overall acceleration or deceleration injury (Schleudertrauma or jolting trauma), is a complex multifaceted phenomenon in which cervical injuries are only a small part of the overall spinal injury and its consequences in other areas of the body. Spinal MRIs, not only those of cervical spine, should be more frequently performed on injured motorists.

The severity of whiplash injury is indicated also by the presence of neuropsychological symptoms, e.g., as assessed via Rivermead Post-Concussion Symptoms Questionnaire [7] and the Subjective Neuropsychological Symptoms Scale (SNPSS).[6] As shown by very low correlation coefficients of such neuropsychological symptoms (i.e., post-concussive and whiplash symptoms) to the neck pain, lower back pain, and headache, these neuropsychological symptoms appear to constitute a relatively independent but important part of whiplash injuries. The subjectively perceived neuropsychological injuries can rapidly and easily be assessed in a preliminary manner by scales such as the Rivermead or the SNPSS in order to triage post-MVA patients for further assessments by rehabilitative neuropsychologists, if needed.

\section{Conclusions}

The locations of pain most frequently reported by chronic post-MVA patients were in the head $(89.9 \%)$, neck (88.6\%), shoulders $(80.4 \%)$, and lower back $(77.8 \%)$. WAD studies that exclude patients with lower back pain might exclude about $82.9 \%$ of injured motorists: the remaining $17.1 \%$ of patients with injury only to the neck are presumably those less adversely affected by the MVA than patients with pain in multiple locations.

Unfortunately, the QTF report has misled many lay 
persons (clerks of car insurance companies, arbitrators, and some health professionals) into thinking that whiplash injuries result only in temporary "discomfort," are "usually self-limited," and have a "favorable prognosis," and that the "pain [resulting from whiplash injuries] is not harmful".

The WAD classification system promoted by the QTF needs to be re-categorised as specific to neck injury only, as WAD-C. Parallel WAD systems need to be introduced both for lumbosacral spine (as WAD-LS) and for the thoracic spine (as WAD-T), to avoid perpetuating the popular misconception that acceleration or deceleration injury (Schleudertrauma, jolting trauma) to the spine is sufficiently assessed by focusing on the cervical injuries only. The use of separate parallel WAD classifications for the cervical, lumbosacral, and thoracic spine (WAD-C, WAD-LS, and WAD-T) would result in more precise clinical assessments and also in more precise research studies.

Furthermore, this new classification system will also preclude the possibility of genuinely injured and disabled patients from being deprived of necessary medical interventions and financial compensation.

\section{REFERENCES}

[1] Fakharian E, Mohammadzadeh M, Saberi HR, Fazel MR, Rejali M, Akbari H, Mirzadeh AS, Mohammadzadeh J. Spinal injury resulting from car accident: Focus to prevention. Asian Journal of Neurosurgery. 2017;12(2):180-184. doi: 10.4103/1793-5482.152110: 10.4103/1793-5482.152110.

[2] Robertson A, Branfoot T, Barlow IF, Giannoudis PV. Spinal injury patterns resulting from car and motorcycle accidents. Spine (Phila Pa 1976). 2002;27(24):2825-30. doi: 10.1097/00007632-20021215000019.

[3] Freeman MD, Croft AC, Nicodemus CN, Centeno CJ, Elkins WL. Significant spinal injury resulting from low-level accelerations: a case series of roller coaster injuries. Archives of Physical Medicine and Rehabilitation. $2005 \quad$ Nov;86(11):2126-30. doi: 10.1016/j.apmr.2005.05.017.

[4] Fast A, Sosner J, Begeman P, Thomas MA, Chiu T: Lumbar spinal strains associated with whiplash injury: A cadaveric study. American Journal of Physical Medicine and Rehabilitation. 2002;81:645-650.

[5] Cernovsky Z, Mann S, Diamond DM, Persad E, Oyewumi LK, Velamoor V, Mendonça J, Woodbury-Fariña MA, and Husni M Critical Review of the Content Validity of Miller Forensic Assessment of Symptoms Test (M-FAST). Archives of Psychiatry and Behavioral Sciences. 2020;3(2):16-29.

[6] Cernovsky ZZ, Litman LC, Mann SC, Oyewumi LK, Bureau Y, Mendonça JD, Diamond DM, and Raheb H. Validation of the Subjective Neuropsychological Symptoms Scale (SNPSS) in Injured Motorists. Archives of Psychiatry and Behavioral Sciences. 2021;4(1):6-13.

[7] King NS, Crawford S, Wenden FJ, Moss NEG, Wade [1] DT. The Rivermead Post Concussion Symptoms Questionnaire: a measure of symptoms commonly experienced after head injury and its reliability. Journal of Neurology. 1995;242:587-592.

[8] Cernovsky ZZ, Mann SC, Velamoor V, Oyewumi LK, Diamond DM, Litman LC. Validation of the Rivermead Post-Concussion Symptoms Questionnaire (RPQ) on Patients Injured in High Impact Car Accidents. Archives of Psychiatry and Behavioral Sciences. 2021;4(1):14-22. doi.org/10.22259/2638-5201.0401003.

[9] Cernovsky Z, Istasy P, Bureau Y, Chiu S. Scale for retrospective assessment of immediate concussion symptoms. Mental Illness. 2018;10(2):70-71, and Appendix (2 pages).

[10] Morin CM, Belleville G, Bélanger L, and Ivers H. The insomnia severity index: psychometric indicators to detect insomnia cases and evaluate treatment response. Sleep. 2011; 34:601-608.

[11] Weathers FW, Litz BT, Keane TM, Palmieri PA, Marx BP, Schnurr PP. The PTSD Checklist for DSM-5 (PCL-5). The National Center for PTSD, US Department of Veterans Affairs, Washington, DC, 2013. www.ptsd.va.gov.
[12] Cleeland CS. The Brief Pain Inventory - User Guide. Houston, TX: The University of Texas - M. D. Anderson Cancer Center, 2009.

[13] Pinfold M, Niere KR, O'Leary EF, Hoving JL, Green S and Buchbinder R. Validity and internal consistency of a WhiplashSpecific disability measure. Spine. 2004;29(3): 263-268.

[14] Spitzer WO, Skovron ML, Salmi LR, et al. Scientific monograph of the Quebec Task Force on Whiplash Associated Disorders: redefining "whiplash" and its management. Spine. 1995;20(8 Suppl):1S-73S.

[15] Freeman MD, Croft AC, Rossignol AM. "Whiplash associated disorders: redefining whiplash and its management" by the Quebec Task Force. A critical evaluation. Spine. 1998;23:1043-9.

[16] Teasell RW, Merskey H. The Quebec Task Force on whiplashassociated disorders and the British Columbia Whiplash Initiative: A study of insurance industry initiatives. Pain Research and Management. 1999;4(3):141-9.

Zack Z. Cernovsky was born in 1947 and holds the Ph.D. in clinical psychology from the University of Zürich, Switzerland, 1986. He is the professor of psychiatry in the medical school of Western University, Canada. Professor Cernovsky has published close to 200 scientific articles in the field of psychiatry and medical psychology, and also chapters in university textbooks.

Stephan C. Mann was born on May 6, 1948 in Philadelphia, Pennsylvania, USA. He received his medical degree from the Sidney Kimmel Medical College of Thomas Jefferson University where he also completed his residency in psychiatry. He worked for the United States Veterans Health Administration for over thirty years and retired as Chief of Mental Health \& Behavioral Sciences at the Louisville VA Medical Center, Louisville, KY. He is currently in private practice. Dr. Mann has previously held faculty positions as Professor of Psychiatry at both the University of Pennsylvania School of Medicine and the University of Louisville School of Medicine. He is a Distinguished Life Fellow of the American Psychiatric Association and is certified by the American Board of Psychiatry and Neurology. He has published almost one hundred scientific publications including three books. Dr. Mann's main research focus includes neuroleptic malignant syndrome, malignant catatonia, tardive dyskinesia, and the neurobiology of schizophrenia.

Varadaraj R. Velamoor graduated in Medicine from Osmania University in India and received his training in Psychiatry in the United Kingdom. He is currently Professor of Psychiatry at the Northern Ontario School of Medicine as well as Professor Emeritus at the Western University School of Medicine. He was previously on Faculty at Cornell University. Professor Velamoor has published over a hundred scientific articles as well as book chapters and psychiatric monographs, including in the area of the Neuroleptic Malignant Syndrome and also on suicidal behavior. $\mathrm{He}$ received Fellowships from the Royal College of Psychiatrists, UK, as well as the American Psychiatric Association.

L. Kola Oyewumi completed his medical training from the University of Ibadan, Nigeria, and the residency training in Psychiatry from the University of Ottawa, Canada. He is a Fellow of the Royal College of Physicians and Surgeons of Canada, a Diplomate of the American Board of Psychiatry and Neurology, and A Distinguished Fellow of the Canadian Psychiatric Association. He was a full-time tenured Professor of Psychiatry, Biomedical and Molecular Sciences and Psychology at Queen's University, Kingston, Canada until retirement in 2012. He was then awarded the Professor Emeritus status at Queen's University. Professor Oyewumi has authored numerous peer-reviewed articles, scientific abstracts, presentations, reports, book chapters and the book: Managing Side Effects of Psychotropic Medications - A handbook for healthcare professionals. His research focus was on "Judicious use of psychotropic medications," with emphasis on early detection and intervention in Mental Health; as well as strategies for treatment- resistant Psychoses. 